\title{
Integrated Approach Towards Water Pollution Control*
}

\author{
ZAHEER Iqbal CUI Guangbai \\ ( College of Water Resources and Environment, Hohai University , Nanjing 210098 ,P. R. China)
}

\begin{abstract}
In this paper, river water quality prediction is integrated with water pollution control measures. Two parameters, water environmental capacity and Pollution Index are selected for pollution control measures. The objective is achieved after the development of simulation model using one-dimensional advection dispersion equation. The model algorithm and computer program is an improvement over the existing water quality models , since the model solution involves four point implicit upwind schemes for water quality prediction and pollution control measures at each grid point. Model simulation results the assessment of water environmental capacity that yield the acceptable and realistic pollutants concentration in order to maintain water quality objectives. The pollution and overall pollution index of the river is suggested for integrating number of contaminants variables into one index. Study provides the mathematical and scientific procedure for water quality management. The new approach is helpful for the water pollution control and to study the impacts of waste effluents on the river system for strategic planning purposes.
\end{abstract}

Key Words Integrated approach, pollution control model , environmental capacity , pollution index , river water quality

The effect of human's activities on surface water system must be anticipated to prevent undesirable environmental consequences against the discharge of waste materials. A number of analytical models , simulation models and solution procedure have been developed for the assessment of water quality for surface water pollution control ${ }^{[1} 1_{2}^{2}$. More recently, a large number of water quality models have been developed for their application to river pollution monitoring ${ }^{[3]}$. Further , the availability of the computer enables the development of mathematical models. One example of such model is enhanced stream water quality, QUAL2 $E^{[4]}$ steady state model and SYSTEM $\Pi^{[5]}$. The development of such models has been continued, but hampered somewhat by inability to identify and quantify the multiple issues required for water environmental pollution control. Moreover the uses of such models are limited for prediction of contaminants rather then pollution control in the water bodies. The approach requires a clear understanding of the underlying philosophy of environmental impact assessment $(E I A)$ and the use of computer based techniques to handle water quality / quantity simulation and pollution control methodology ${ }^{[6]}$. A new approach is advisable to construct a framework to integrate river water quality $(R W Q)$ with water pollution control measures including water environmental capacity ( WEC) and pollution index $(P I)$. 
In the present research one dimensional water environmental pollution control model is developed using numerical solution of advection dispersion equation using finite difference method ( FDM ). For each grid point, $R W Q, W E C$ and $P I$ are simulated with upwind implicit scheme using double sweep method. This method uses the band matrix structure of the linear system of the equation to compute the solution with number of operations proportional to $\mathrm{n}$. More detail on double sweep method, the algorithm as applied to the Abbott-Ionescu type scheme for the river flow computation may be found in the original reference each grid point along the river reach ${ }^{[7]}$. The model is applied in the middle downstream reaches of Hanjiang River, flowing from Danjiangkou reservoir in the north of China and ends at the confluence with Yangtze River. The discharge of waste materials collected from domestic and industries points of sources is showing the adverse impacts on the existing water quality and water environment of the river. The model simulated results helps to predict downstream water quality, water environmental capacity and establishment of river pollution index. It is shown from the literature that for water environmental pollution control measures $W E C$ describes the most capacity of absorbing pollutants of the river as it satisfies the given water quality standards ${ }^{[8]}$. Moreover, with the help of PI and overall $P I$, many contaminants pentameters are integrated into one comprehensive index values ${ }^{[9]}$. First , the model is calibrated to fix the values of model coefficients with the use of field observed data. Further the model is verified without changing the values of coefficients for its application to control water pollution of Hanjiang River.

\section{Water Pollution Control Model}

The model includes a set of mathematical expression defining the physical, chemical and biological processes that are assumed to take place in the river system. In the theoretical form, it assigns numerical values to model parameters , incorporating some prior observation drawn from the field and laboratory data, and relating external input.

The model configuration comprises of four components grasping the close linkage and interaction between each part. However, each part implicated individually using the simulated data results the individual output.

\subsection{Flow Computation Sub-Model}

The model is based on the one dimensional shallow water equation called de-saints Venant's equation of mass continuity and momentum of the fluid mechanics. Gradually varied unsteady flow in open channels mathematically described by this equation ${ }^{[10]}$. The full partial differential equation with no lateral flow is expressed as

Continuity equation $: B \frac{\partial Z}{\partial t}+\frac{\partial\left(B H_{u}\right)}{\partial x}=q$

Momentum equation : $\frac{\partial z}{\partial t}+u\left[\frac{\alpha u^{2}}{\partial x}\right]+g \frac{\partial Z}{\partial x}+g \frac{u^{2}}{K^{2}}=0$

where $K=4 C \sqrt{R}, C=\frac{1}{n} R^{1 / 6}, Z$ is the local elevation of water surface $(\mathrm{m}), Q$ is river discharge $\left(\mathrm{m}^{3} / \mathrm{s}\right), x$ corrdinate along the river flow,$t$ time variable $(s), C$ is Chezey constant,$g$ is accelera- 
tion due to gravity $\left(\mathrm{m}^{2} / \mathrm{s}\right), K$ is the conveyance and $B$ river breadth $(\mathrm{m})$. The both equations can be written in the difference from for each river cross section as :

Continuity equation $: Q_{i}-Q_{i-1}=\Sigma Q_{\text {in }}-Q_{\text {out }}$

Momentum equation $: Z_{i-1}-Z_{i}=\left[\left(\frac{Q_{i}-Q_{i-1}}{2}\right)^{2} \cdot n_{i-1}^{2} / A / B\right] \Delta x_{i-1}+\frac{1}{2 g}\left(\frac{Q_{i}^{2}}{A_{i}^{2}}-\frac{Q_{i-1}^{2}}{A_{i-1}^{2}}\right)$

where $A=\left(\frac{A_{i}-A_{i-1}}{2}\right)^{2}, B=\left(\frac{R_{i}-R_{i-1}}{2}\right)^{\frac{3}{4}}, R$ is hydraulic radius and $\mathrm{n}$ is manning coefficient. Model simulation results hydraulic and hydrological parameters including water discharge $(Q)$, water stage $(Z)$, flow velocity $(U)$, and water depth $(h)$ at each river cross-section.

\subsection{Water Quality Prediction Sub-Model}

One-dimensional advection-dispersion equation is used for the downstream pollutants prediction and transport after the discharge of wastewater. The pollutants are evenly distributed within the river section due to the effect of advection, dispersion and dilution. Presently, the model is used for the prediction of $\mathrm{COD}, \mathrm{BOD}_{5}, \mathrm{NH}_{3}-\mathrm{N}$ and $\mathrm{DO}$. The governing equation is given as below ;

$$
\frac{\partial C}{\partial t}+u \frac{\partial C}{\partial x}=\frac{\partial}{\partial x}\left[\left(D_{L}+E_{x}+E_{m}\right) \frac{\partial C}{\partial x}\right]-K_{c}+S
$$

where $u$ is average flow velocity $(\mathrm{m} / \mathrm{s}), C$ is pollutant concentration $(\mathrm{mg} / \mathrm{L}), K_{c}$ is decay coefficient $\left(\mathrm{d}^{-1}\right), E_{x}$ and $E_{m}$ is advection and molecular diffusion coefficient $\left(\mathrm{m}^{2} / \mathrm{s}\right)$ and $S$ is pollutants source and $\operatorname{sink}(\mathrm{mg} /(\mathrm{L} \mathrm{s}))$. Using Finite difference method, the above equation is written as in the following difference form ;

$$
\frac{C_{i}^{n+1}-C_{i}^{n}}{\Delta t}+u_{i} \frac{C_{i}^{n}-C_{i-1}^{n}}{\Delta x}=E_{i} \frac{C_{i+1}^{n+1}-2 C_{i}^{n+1}+C_{i-1}^{n+1}}{\Delta x^{2}}-\frac{K_{i}\left(C_{i}^{n+1}+C_{i-1}^{n}\right)}{2}+S_{i}
$$

The above equation is numerically solved by upwind implicit scheme using double sweep method to simulate the pollutants concentration at each cross section. Double sweep method uses the banded matrix structure of a linear system of equation to compute the concentration at each cross section. In this method for one-dimensional river reaches under one boundary condition given at each end, the coefficient matrix contains element only in the band along the main diagonal.

\subsection{Boundary Condition}

Boundary of one-dimensional advection diffusion equation possesses the following form :

(1) Close boundary condition, i. e. $\partial c / \partial n=0 ;(2)$ Pollution source boundary condition : $C$ (pollutants concentration) ; (3) Open boundary condition, i.e. $\partial^{2} c / \partial n^{2}=0$.

For the transport of pollutants in one dimensional river course , open boundary condition is considered.

\subsection{Water Environmental Capacity Sub Model}

Model formulation for the calculation of water environmental capacity is based on the law of conservation of pollutants. It is described on the basis of one dimensional convection-diffusion equation for the transport and decomposition of pollutants at various cross sections with following relation ;

$$
\frac{\partial(A C)}{\partial t}+\frac{\partial(Q C)}{\partial x}-\frac{\partial}{\partial x}\left(A E_{x} \frac{\partial C}{\partial x}\right)+K A C-W=0
$$


Integrating both side of equation at $(0, x)$, we get ;

$$
W=\frac{\partial}{\partial t} \int_{0}^{x} A C d x z+\int_{0}^{x} A K C d x+Q_{x} C_{x}-Q_{0} C_{0}-\left.A E_{x} \frac{\partial C}{\partial x}\right|_{x=0} ^{x=x}
$$

where $W$ is the amount of effluent discharged per second from the point source into the river reach , $Q_{0}, C_{0}$, are the discharge and concentration at $x=0$, while $Q_{x}$ and $C_{x}$ are the values at distance $x$. The second term on the right side of the equation describes the self-purification of the pollutants when $K$ is constant ;

Integrating continuity equation $; \frac{\partial C}{\partial x}+B_{T} \frac{\partial Z}{\partial t}=q_{1}$ at $[0, x]$ yields $\frac{\partial V}{\partial t}+\left(Q_{x}-Q_{0}\right)=q$, where ,

$$
\begin{aligned}
& q=\int_{0}^{x} q_{1} \mathrm{~d} x \text {, is effluent quantity, then equation } 8 \text { becomes; } \\
& \qquad W E C=Q_{0}\left(C_{s}-C_{0}\right)+q C_{s}+K V C_{s}
\end{aligned}
$$

$Q_{0}$ and $C_{0}$ are upstream discharge and pollutants concentration, $C_{s}$ is permissible limits of pollutants , $q$ and $V$ is section discharge and volume. In the right side of equation, the first term is called as dilution term; second term is referred as addition term and third is called as self-purification term. The WEC calculated by this method is called as complex method. WEC is also calculated by simplified method while considering self-purification or assimilation capacity by simplified equation 9 , as $W E C=$ $K V C_{s}$ when , $C_{0}=C_{s}$ and $q<K V$. This is referred as a threshold value when it does not possess any ability for dilution and lateral carrying capacity. Both equations are used to calculate permissible discharged quantity and WEC of each section respectively. They are used in presence of effluents. If $C_{0}$ is unknown, the water quality prediction sub-model integrated to calculate $W E C$ of the section whose $\mathrm{u} / \mathrm{s}$ pollutants concentration known .

\subsection{Pollution Index Sub Model}

The Pollution Index expressed as relative value of $C_{i}$ the multiple contaminant water quality parameters and $L_{i j}$ is permissible limit of the respective contaminants. The index is expressed by using average and maximum values ;

$$
P I_{j}=f\left[\max . \text { of }\left(\frac{C_{i}}{L_{i j}}\right)^{\prime} s \text { and mean of }\left(\frac{C_{i}}{L_{i j}}\right)^{\prime} s\right]
$$

where $P I_{j}$, described as the weighing factor for the particular use of water. Its value can be measured as length of radii of the concentric circle, which is obtained by drawing the graph between max and mean values, so the relation in equation (10) can be expressed as below :

$$
P I_{j}=m \sqrt{\max .\left(C_{i} / L_{i j}\right)^{2}+\operatorname{mean}\left(C_{i} / L_{i j}\right)^{2}}
$$

Hence $m$ is the proportionality constant and its value can be calculated as , $1.0=m \sqrt{1^{2}+1^{2}}$, i.e. $m=\frac{1}{\sqrt{2}}$. When index of use $\mathrm{j}$ is expressed as 1.0 when all items of water quality are equal to their respective permissible limits for the respective use , then expression of pollution index for particular use $P I_{i}$ as follow : 


$$
P I_{j}=\sqrt{\frac{\max \left(C_{i} / L_{i j}\right)^{2}+\operatorname{mean}\left(C_{i} / L_{i j}\right)^{2}}{2}}
$$

The $P I_{i}$ in the above equation is the proposed Pollution Index only for particular water use such as drinking, swimming, industrial and agriculture under the given permissible limits.

Overall Pollution Index is used to analyze the pollution control problems for the multiple uses of water in the region. It is obtained by the modification of equation (12) , by employing the overall permissible limits for $L_{i j}{ }^{\prime} s(j=$ all uses $)$. Overall Pollution Index is for general use is calculated as a weighted average value for all the PI's as follows :

$$
P I=\sum_{j=1}^{j-n}\left(w_{j}, P I_{j}\right)
$$

where $w_{i}$, is weight coefficient constant values), which is determined by the relative importance of $j$ water use in the region and $n$, is numbers of water uses. Model is simulated in establishing the Pollution Index for the expression of pollution quality of multiple waters uses and over all $P I$ for the general uses of water.

\section{Model applications}

The model is applied for the pollution control of water environment of Hanjiang River using existing water quality prediction. The total length of river of lower and middle reaches is about $640 \mathrm{~km} \mathrm{cov-}$ ering the basin area of 6 million square $\mathrm{km}$. The main source of pollution is domestic, agriculture and industrial. The main stream of Hanjiang River is divided into all together in 7 sections , Laohekou , Xiangfan , Yichen , Zhong Xiang, Zekou , Xiantao , and Wuhan. for the model simulation. Mouth of each section marked as the point sources for the discharge of effluents into the main river. Each section is further divided into cross section for the solution computation ${ }^{[11]}$. Model simulation predict the hydrological and water quality variables ( $\mathrm{COD}, \mathrm{BOD}_{5}, \mathrm{NH}_{3}-\mathrm{N}$ and $\left.\mathrm{DO}\right)$ from beginning to end of the sections. Some parameters like degradation, re-aeration, river bottom drag and roughness coefficients were calculated. The methods have been employed to integrate predicted values for the assessment of water environmental capacity and calculation of pollution index among the river sections.

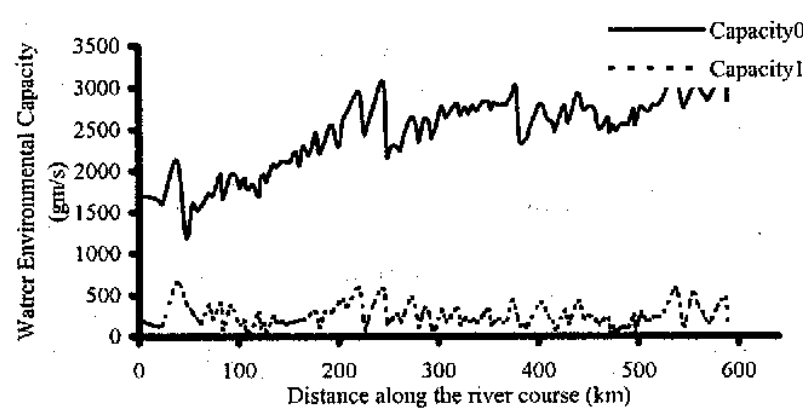

Fig. 1 Computation of water environmental capacity of Hanjiang River using complex and simplified method
2. 1 Assessment of Water Environmental Capacity

The simulation results the environmental capacity at each segment between two adjacent sections. Considering the Hanjinag River, main pollutants are the wastewater is from mining industries and domestic. Water pollutant type is mainly organic, producing $\mathrm{COD}_{\mathrm{Mn}}$ as representative for the change of water environmental capacity ( Tab. 1). For computation of WEC, the permissible concentration of 
$\mathrm{COD}_{\mathrm{Mn}}$ is taken in accordance to class II of Chinese nation standards (GB 3838-88) of surface water. Environmental capacity is assessed based on two factors ; a) the diluting capacity ( capacity0) or water environmental absorbability which , cause to decrease the carrying capacity of then river and it subsides the effect of the pollutants and distribute the pollutants gradually in water and bottom soil, and b) the self purification or assimilation capacity (capacity1) which, causes the decrease of pollutants to harm less level under the influence of certain chemicals, physical and biological process in the river referred as river threshold capacity ( Tab. 2) . WEC is found to be linear function of the river course storage capacity and water flow as shown in the Fig. 1. The graph pattern shows the distribution of water environmental capacity involve social economy, technology and management etc, distributed principle is found little bit complicated, based on three type of principle, a) minimum cost principle , according to minimum regional environmental capacity , minimum treatment cost principle , b) impartial reasonable principle , according to more or less influence of water quality to reduce pollution load principle , and c) equal ratio distribution, according to existing pollution , environmental capacity equal ratio distribution on each pollution source, the more pollution load , the more distribution of environmental capaci$\mathrm{ty}^{[12]}$. Model procedure yields the acceptable and realistic concentration of chemical oxygen demand reduction required to maintain the present water quality standards, which is based on the water self purification phenomena. Moreover, the existing water quality, design water quantity and flow rate the critical factors that define the regime and unit environmental capacity.

Tab.1 Computation of water environmental capacity based on COD concentration

\begin{tabular}{cccccccc}
\hline \multirow{2}{*}{$\begin{array}{c}\text { River } \\
\text { Sections }\end{array}$} & $\begin{array}{c}\text { COD } \\
\text { Waste Load } \\
(\mathrm{gm} / \mathrm{s})\end{array}$ & $\begin{array}{c}\text { Cal. } \\
(\mathrm{mg} / \mathrm{L})\end{array}$ & $\begin{array}{c}\text { Obs. } \\
(\mathrm{mg} / \mathrm{L})\end{array}$ & $\begin{array}{c}\% \\
\text { Error }\end{array}$ & $\begin{array}{c}\text { Capacity 0 } \\
(\mathrm{gm} / \mathrm{s})\end{array}$ & $\begin{array}{c}\text { Capacity 1 } \\
(\mathrm{gm} / \mathrm{s})\end{array}$ & $\begin{array}{c}\text { River } \\
\text { Absorbability }(\%)\end{array}$ \\
\cline { 3 - 8 } & 200 & 2.530 & 2.22 & 14.0 & 1201.06 & 405.43 & 33.55 \\
24 & 300 & 2.195 & 2.5 & -12.2 & 1689.98 & 285.69 & 16.91 \\
35 & 200 & 2.031 & 1.7 & 19.5 & 2071.53 & 197.74 & 9.54 \\
51 & 450 & 2.059 & 2.2 & -6.4 & 2167.53 & 161.29 & 7.44 \\
82 & 450 & 1.942 & 1.9 & 2.2 & 2363.85 & 125.06 & 5.29 \\
98 & 195 & 1.826 & - & - & 2513.93 & 143.18 & 5.69 \\
139 & 200 & 1.633 & 1.7 & -3.09 & 2851.20 & 143.07 & 5.01 \\
\hline
\end{tabular}

Tab.2 Pollution and overall pollution index for different uses computed at various cross sections

\begin{tabular}{ccccc}
\hline \multirow{2}{*}{ River sections } & \multicolumn{3}{c}{ Pollution indices } & \multirow{2}{*}{ OVPI } \\
\cline { 2 - 4 } & PINDEX - & PINDEX -2 & PINDEX -3 & 1.56 \\
8 & 3.34 & 0.25 & 0.36 & 0.87 \\
35 & 1.82 & 0.25 & 0.21 & 0.84 \\
51 & 1.76 & 0.24 & 0.21 & 1.44 \\
82 & 3.09 & 0.34 & 0.33 & 0.51 \\
98 & 0.99 & 0.21 & 0.17 & 0.64 \\
139 & 1.32 & 0.21 & 0.17 & 1.29 \\
\hline
\end{tabular}

\subsection{Calculation of Pollution and Overall Pollution Index}

For the pollution index, the level of water quality at different reaches of the river is used during the model simulation. The relative values of predicted concentration of each water quality parameter and their respective permissible limited is taken as 1.0 , is the critical value i.e. the value greater 
than 1.0 indicate that the water requires some treatment before specific uses $\left(J_{i s}^{\prime}\right)$ according to the Chinese National standards of surface water quality. Specifically , relatively simple index called pollution index is calculated. Although three pollutants variables are discussed in this paper, more than three variables can be included in the index depending on the availability of data. This index is calculated only for the particular use, however it is modified to calculate for overall pollution index for some sort of group uses , depending upon what kind of permissible level is employed as $L_{i j}^{\prime} s$. If the $L_{i j}^{\prime} s$ are determined from the general permissible level for drinking, fishing and recreation as an example, the index $P I_{j}$, may be defined as the index for outdoor general use. The pollution index values for three specific uses $\left(P I_{j}\right)$, drinking and fisheries ( PINDEX - 1), industrial and recreational ( PINDEX - 2) and agriculture (PINDEX - 3 ) for all sections of the

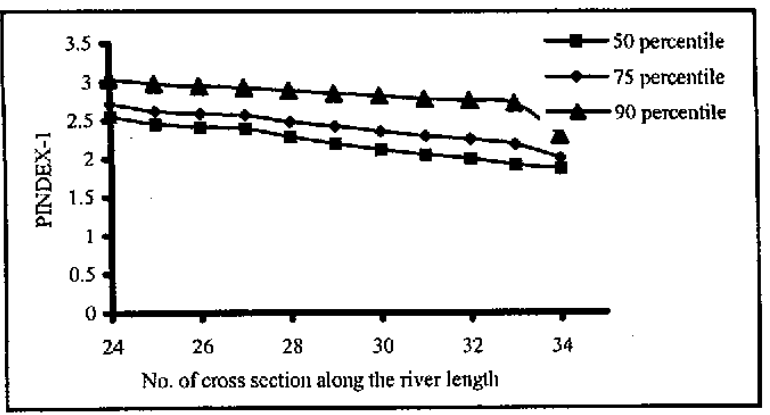
main river are computed and plotted. Similarly, overall pollution index is computed for some sort of group uses depending upon kinds of permissible level is employed and weight coefficient $\left(w_{j}\right)$ (Fig.
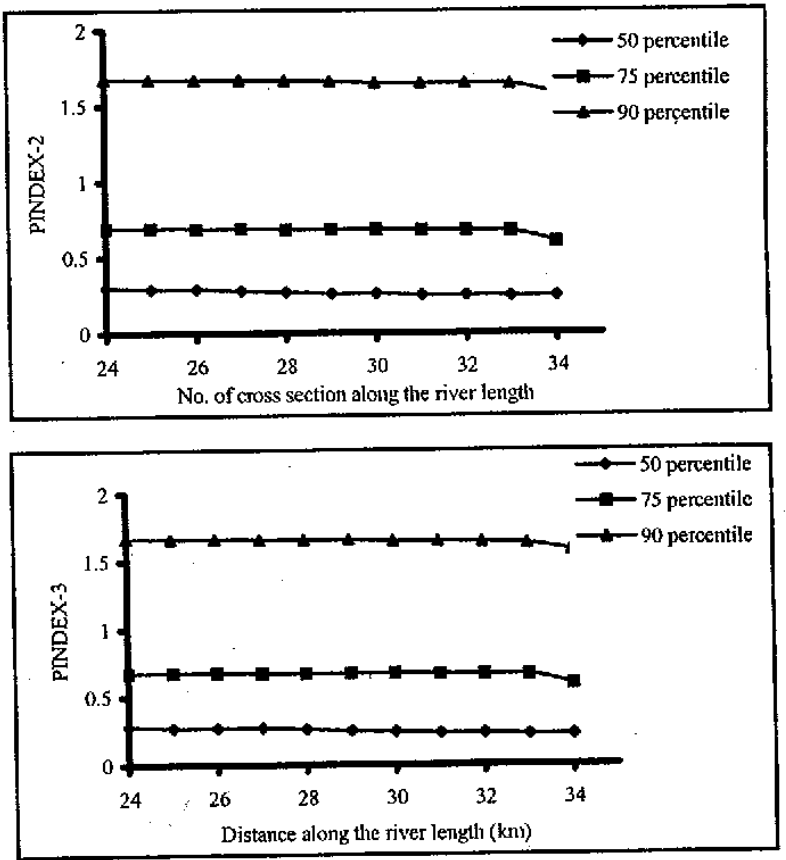

2 ). Weight coefficient is determined by the relative importance of water uses $\mathbf{J}$, is taken as 1.0 . The purpose of method is applied for integrating many contaminants pentameters into one index for general uses of water. The relative values of pollution index depend upon the concentration of permissible water quality variables. Tab. 2 is showing the computed value of pollution and overall pollution index all sections along the main river. The probability curves of the values of the various parameters collected are plotted. The values of Pollution Index is computed for the period of ten days and plotted for 50,75 and 90 percentile values at each cross section selected water uses (Fig. 3). Each percentile value shows that, as for example, for 75 percent of the observation is less than it and 25 percent greater than it. The main purpose of water utility and all existing water in the region should be taken into the con- 


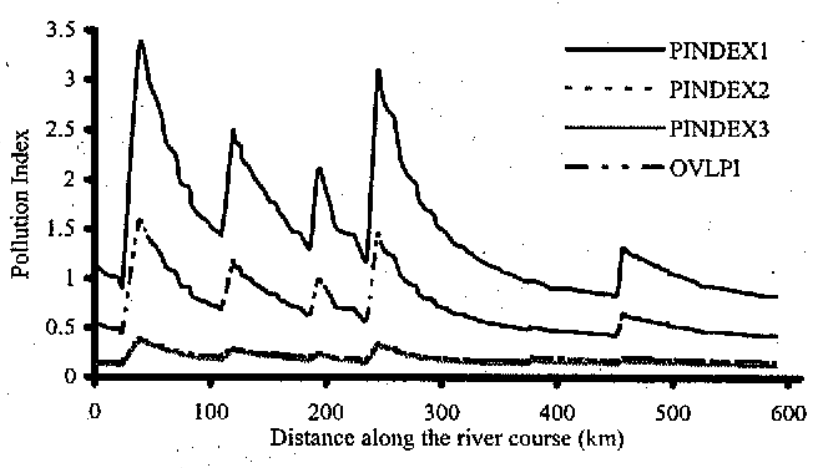

Fig.3 Computed values of pollution index for various water uses of Hanjiang River sideration in the regional benefit analysis of water pollution control problems ${ }^{[13]}$.

\section{Conclusions}

The model algorithm and computer program used in this model is an improvement over the existing water quality models, since the model simulation results the integrated approach towards water pollution control of the river system using predicted water quality and quantity of the river. The assessment of water environmental capacity of the Hanjiang River gives a possible solution for the river pollution abatement. Due to the facts a) too little oxidation treatment before discharge results in potential stream pollution from oxygen consumption , b) and too much oxidation treatment can place an unnecessary heavy financial burden upon the producer of product and service, the present study provides the mathematical and scientific procedure that will yield the acceptable concentration of COD reduction required to maintain existing water quality standards. Results show, environmental capacity distribution is described as equal ratio distribution principle, giving consideration to others. Pollution and overall pollution index is the most important part of the act influencing the activities of pollution control. Weight coefficient is important factor for proposing the relative importance of water use in the region, which helps in controlling and adjusting effluents potential in to the river for desired water quality. Both $W E C$ and $P I$ of the river improve and sustain the quality management in protecting the river water environment. The approach used in the developed model is helpful for the pollution control of rivers of similar nature.

\section{References}

1 Streeter H W , Phillips E B. A study of pollution and natural purification of Ohio River. Publ Health Bulletin , 1925 , Wash No 146

2 Robert L R. Solution of advection dispersion equation , continues load of first duration. J Environ Eng , $1996: 830$ - 831

3 Andreja D Jana Z. K. Water quality modeling of River Sava, Slovenia. Wat Res , 1996,30 (11) $2587-2592$

4 Brown L C ,Barnwell J O Jr. The enhances stream water quality model QUAL2E and QUAL2E-UNCAS Documentation and user manual , 1987 USEPA/600/3 - 87/007

5 Falconer R A. Water Quality modeling. Institute of Water and Environmental Management , 1996 , UK

6 Zaheer I. Environmental Impact Assessment, Implementation and Improvement-A Case Study. CEWRE , 1994 , (2) , 34 - 39

7 Cunge J A , Holly F M. Practical aspect of computational river hydraulics. In : Ellis K V ed. Surface water pollution and its control. London : Pitmann Advances Publication , 1989

8 Horton R K. An index number system for rating waters quality. Journal of Water Pol Control , 1965 , 37 (3)

9 Lohani B N ,Chuang M S. Water Classification in the Tanshui River Basin in Taiwan. Water Resources Development , 1987, 3(3) :154 $-164$

10 Zhao D H. Finite volume of two- dimensional unsteady flow model for rivers basin. J of Hydraulic Engineering , 1994 ,120(7) , AS$\mathrm{CE}$ 
11 South West Project of Hanjiang River, Nanjing Institute of Hydrology , China

12 Churchill M A , Buckingham R. A Statistical method for analysis of stream purification capacity. Sew Ind Wastes , 1956, 28(4) : $517-537$

13 Nelson L N. Stream, lake, estuary, and ocean pollution. Environmental Engineering Series ,2nd Ed. Van Nostrand Renhold , NY , 1985

\title{
一种水污染的综合控制模型
}

\author{
扎黑尔 崔广柏
}

(河海大学水环境学院, 南京 210098)

提 要 本文将水质预测及水污染控制措施有机地结合, 选取水环境容量和污染指数作为水污染 控制的参数. 这样, 一维对流一扩散水质方程的求解除就是实现本研究目的的关键. 本研究采用的模型在 现有的水质模型基础上有所改进, 因为其采用四点隐格式对水质进行预测, 推求可接纳污染物的环境容量 值及为保证水质而限定的污染物浓度值, 从而制定相应的水污染控制措施. 为整体考虑各种污染物的情 况 建议采用河流的污染指数进而推求综合污染指数. 总之, 本研究为水质保护提供了科学的计算方法, 该 法对水污染控制及污水对河道水质的影响是实用有效的.

关键词综合法 污染控制模型 环境容量 污染指数 河流水质

分类号 $\mathrm{X} 52$ 